\title{
Implementation of DSP Based Relaying with Particular Reference to Effect of STATCOM on Transmission Line Protection
}

\author{
J.V.V.N Bapiraju, U.J.Shenoy, Senior Member, IEEE, K.G.Sheshadri, H.P. Khincha, Senior Member, \\ IEEE, D.Thukaram, Senior Member, IEEE.
}

\begin{abstract}
The presence of Flexible AC Transmission System (FACTS) devices in the loop significantly affects the apparent resistance and reactance seen by a distance relay, as FACTS devices respond to changes in the power system configuration. The objective of this paper is to investigate the effect of mid-point compensation of STATic synchronous COMpensator (STATCOM) on the performance of impedance distance relay under normal load and fault conditions and to implement the adaptive distance relaying scheme for transmission line protection. From the simulation studies carried out in PSCAD software and using analytical calculations, it is identified that there is a need for the distance relay to adapt to the new settings in its characteristic for the detection of fault within the zone of protection of transmission line. Apparent impedance is simulated for different loading and line to ground (L-G) fault conditions at different locations on the power system network. The proposed adaptive distance relay schente has been implemented on TMS320C50 Digital Signal Processor (DSP) system.
\end{abstract}

Index Terms- Apparent impedance, distance relays, DSP processor TMS320C50, Fourier algorithm, PSCAD/EMTDC, quadrilateral characteristics and STATCOM.

\section{INTRODUCTION}

A daptive relaying [1], [2] scheme in power system -protection involves the use of relays, which may need to change their characteristic to suit the prevailing conditions. Generally a protective system responds in a predetermined manner to any contingency or fault. It is often necessary to make a setting that covers great many conditions and consequently is less suitable for the normal conditions, which the relay would face most of the time. Hence, under certain conditions with appropriate safeguards, it is desirable to make relays adapt to changing conditions.

If there are any FACTS devices present in the loop where

J.V.V.N Bapiraju is with the Department of Electrical Engg., Indian Institute of Science, Bangalore-560 012 (bapiraju@ee iisc.emet.in).

U.J.Shenoy, corresponding author is with the Department of Electrical Engg., Indian Institute of Science, Bangalore-560 012 (ujs@ee,iisc.emet.in).

K.G. Sheshadri is with the Department of Electrical Engg., Indian Iristitute of Science, Bangalote-560 012 (kg sheshadri@yahoo.com).

H.P. Kincha is with the Department of Electrical Engg., Indian Institute of Science, Bangalote-560 012 (hpk(cee.iisc.emet.in).

D. Thukaram is with the Department of Electrical Engg., Indian Institute of Science, Bangalore-560 012 (dtram@ee.iisc.ernet.in). the distance relay zone is defined, the distance relay resistance and reactance reach settings may not be same for all the operating points of the power system. The concept of adaptive relay setting for distance relaying of a transmission system involving FACTS devices has been discussed in [3], [4].

This paper presents the investigation of the effect of mid point compensation of STATCOM on the distance relay settings. A simple transmission system consisting of a generator at sending end, a load at receiving end, transmission line and STATCOM at mid point, has been considered for simulation studies. Apparent resistance and reactance are simulated for different loading conditions, L-G faults, different fault resistances and for the faults created at different locations on the transmission line. All simulation studies have been carried out in PSCAD/EMTDC software [5]. The adaptive distance relaying scheme has been implemented on Texas Instruments TMS320C50 DSP based hardware.

\section{ANALYTICAI CALCULATIONS}

The current (I) and impedance $(Z)$ can be evaluated based on active power $(P)$ and reactive power $(Q)$ as given in (1) and (2). Resistance $\left(R_{\mathrm{a}}\right)$ and reactance $\left(\mathrm{X}_{\mathrm{a}}\right)$ values are normally evaluated using Fourier full cycle algorithm by inputting instantaneous voltage (V) and current (I) values for the distance relay. Apparent resistance and reactance of the distance relay can also be evaluated based on cycle-to-cycle active power and reactive power transfer at relay point as given in (3) and (4).

$$
\begin{aligned}
& I=(P-j Q) / V^{*} \\
& Z=V^{2} /(P-j Q) \\
& R_{a}=\left(V^{2} \cdot P\right) /\left(P^{2}+Q^{2}\right) \\
& X_{a}=\left(V^{2} \cdot Q\right) /\left(P^{2}+Q^{2}\right)
\end{aligned}
$$

Variation of resistance and reactance with respect to reactive power demand for a constant active power demand can be calculated using equations given in (5) and (6).

$$
\begin{aligned}
& \Delta R_{a}=\left\{2 V^{2} \cdot P \cdot Q /\left(P^{2}+Q^{2}\right)^{2}\right\} \cdot(-\Delta Q) \\
& \Delta X_{a}=\left\{V^{2} \cdot\left(P^{2}-Q^{2}\right) /\left(P^{2}+Q^{2}\right)^{2}\right\} \cdot(\Delta Q)
\end{aligned}
$$


It is evident from the above expressions that apparent resistance increases with decrease in the reactive power while apparent reactance decreases with decrease in the reactive power.

\section{EFFECT OF STATCOM}

Applications of STATCOM include voltage control, steady state and transient stability enhancement [6], [7]. The response of STATCOM is very fast, typically 1-1.5 cycles for its reactive power range. In this paper, the effect of the midpoint compensation of STATCOM on the performance of distance relays is considered. Reactive power support from the STATCOM positioned at mid point reduces the burden on the sending end station. The STATCOM responds to changes in the system conditions and maintains the voltage at specified value by controlling its output reactive power.

The term $\triangle Q$ in (5) and (6) represents the difference of reactive power at sending end in the absence and presence of STATCOM at mid point of the transmission line. The decrease in the reactive power demand at sending end with the presence of STATCOM significantly affects the resistance and reactance reach of the distance relay as these values depend on both active power and reactive power flows. Detailed simulation studies have been carried out to find out the apparent resistance and reactance values during normal loading and fault conditions.

\section{POWER SYSTEM MODEL AND STATCOM}

Fig. 1 shows a typical single line diagram of simple power system network modeled using PSCAD/EMTDC software. Sending end substation is modeled with $132 \mathrm{kV}, 100$ MVA generator as fixed source and a short circuit capacity of 2500 MVA. A $60 \mathrm{~km}$ transmission line modeled with 12 PI sections, each $5 \mathrm{~km}$ in length, enables simulation of fault at different line lengths. Line resistance of $0.16 \Omega / \mathrm{km}$, reactance of $0.38 \Omega / \mathrm{km}$ and shunt admittance of $0.000872 \mathrm{mhos} / \mathrm{km}$ have been considered. STATCOM is connected at $30 \mathrm{~km}$ from the sending end station. Apparent resistance and reactance are simulated for different reactive power demand with a constant active power demand of $32 \mathrm{MW}$ at the receiving end. The effect of change in the fault resistance has been studied by simulating L-G fault at different line lengths of transmission line.

A 6 pulse STATCOM is modeled with simple control circuit. Reactive power from the STATCOM is controlled in order to maintain the reference voltage of the STATCOM at the mid point. Phase angle required for sinusoidal Pulse Width Modulation (PWM) is generated using integration of the difference of mid point voltage and reference voltage of the STATCOM as shown in the Fig. 2. This phase shift determines the direction and amount of reactive power flow from the STATCOM. Triangular and reference sinusoidal signals are necessary for PWM technique. First, the triangular signals synchronized with three phase AC system mid point voltages $V_{n a}, V_{n b}, V_{n c}$ have been generated at carrier frequency of 33 times the fundamental as shown in the Fig. 3. The second set of sinusoidal reference signals have been generated by shifting phase angle as shown in Fig. 4. Generation of firing pulses for 6-pulse bridge is shown in Fig.5. The response of STATCOM on the performance of distance relay has to be considered for the changes in reactive power demand at the receiving end.

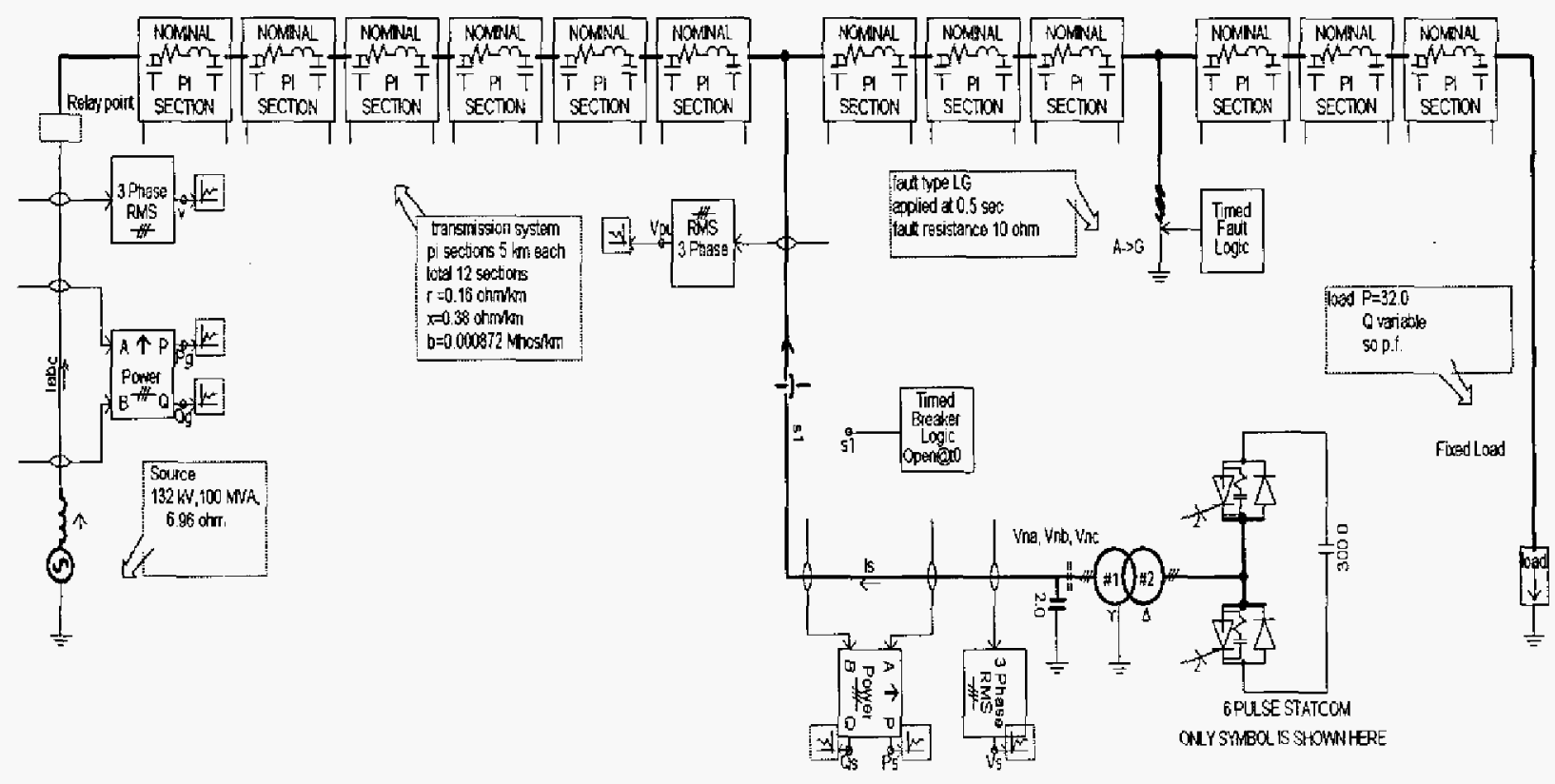

Fig. 1 . Typical power system network for simulation studies 


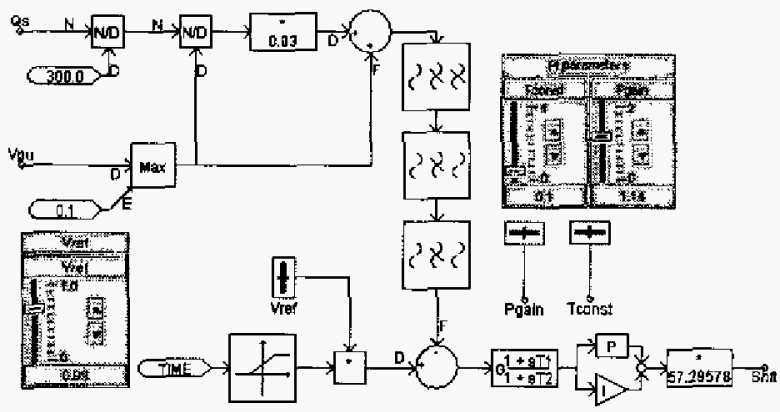

Fig. 2. Genetation of Phase angle order.

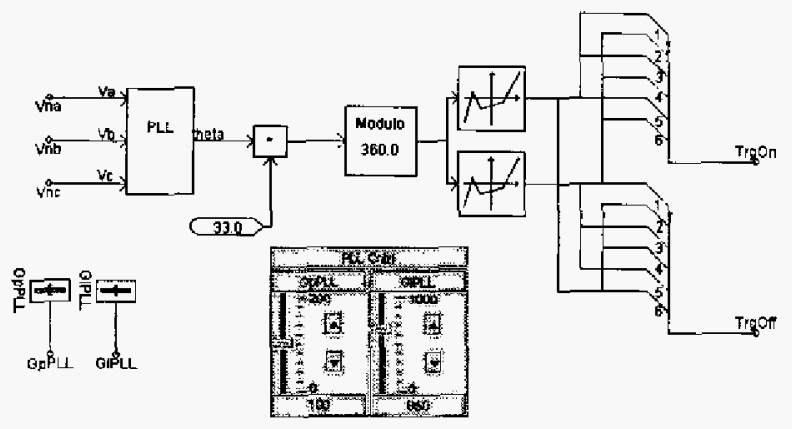

Fig. 3. Generation of Triangular waveforms.

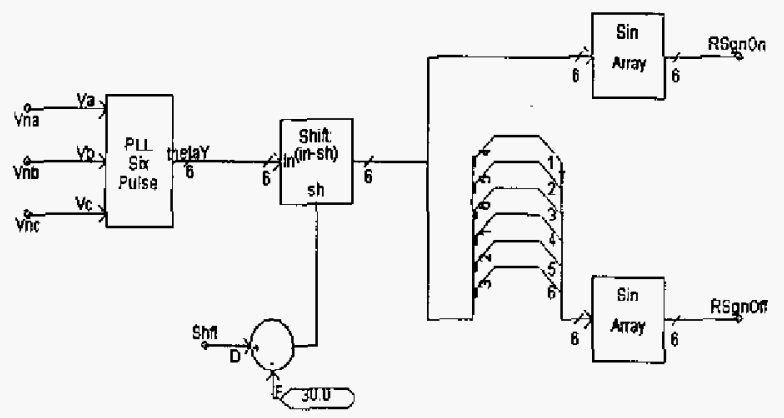

Fig. 4. Generation of reference sinusoidal signals.

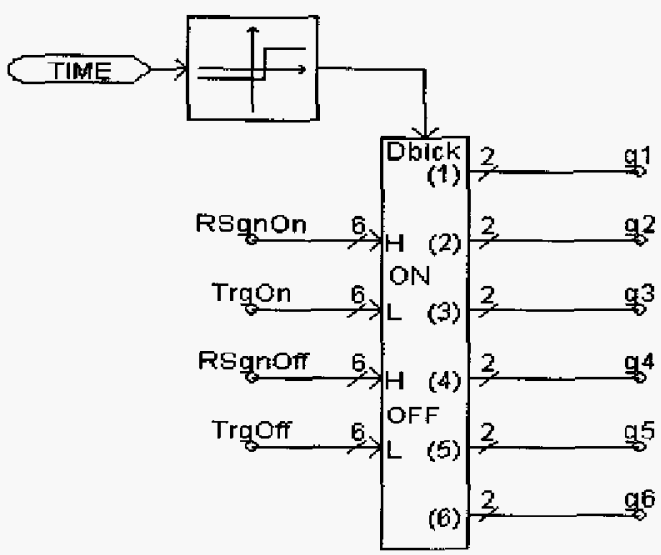

Fig. 5. Generation of gate signals 6 pulse Thyristor Bridge

\section{SIMULATION RESULTS}

Voltage and current data at a sampling frequency of $6 \mathrm{kHz}$ (120 samples per cycle) has been obtained from the simulation studies of PSCAD/EMTDC model, in order to implement the DSP based adaptive relaying scheme. Total time for simulation is 1.0 second. Fig. 6 shows voltages (in p.u.) at relay point and at mid point in the absence of STATCOM. Initially a load of $32.0+\mathrm{j} 32.0 \mathrm{MVA}$ is applied at the receiving end. After 0.5 seconds a $L-G$ fault with fault resistance of 10.0 ohms is simulated at $75 \%$ of $60.0 \mathrm{~km}$ line. Fig. 7 shows the improvement of the voltage profile during normal loading conditions by the inclusion of STATCOM. When the fault is created, STATCOM boosts the voltage by injecting the reactive power. Resistance and reactance of the distance relay are evaluated using Fourier full cycle algorithm by inputting instantaneous voltage and current signals.

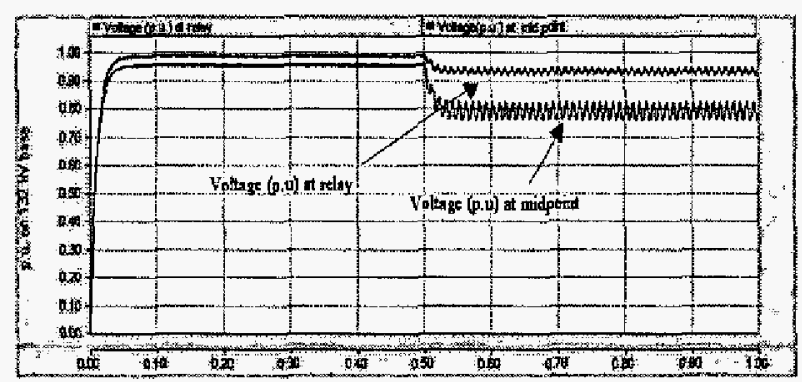

Fig. 6. Voltages without STATCOM.

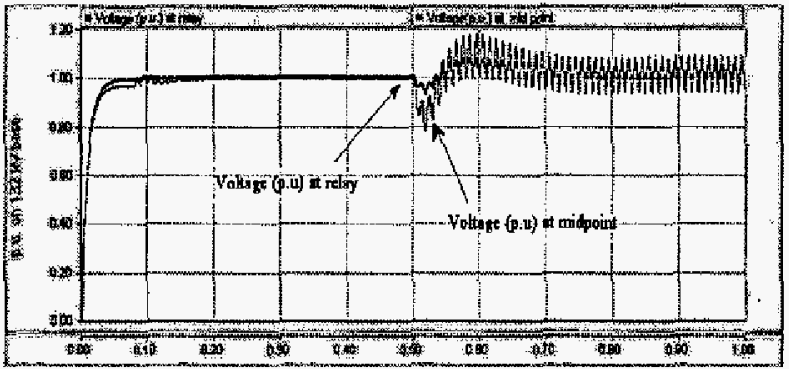

Fig. 7. Voltages with STATCOM.

Table I shows the resistance and reactance variations, with and without STATCOM, for different reactive power demand. It has been observed that the apparent resistance increases with the decrease in the reactive power demand. With increase in the reactive power demand on the receiving end there is a decrease in the apparent reactance at the relay point. This is because of the supply of more reactive power into the system by the STATCOM to maintain the voltage at specified reference value. Table II and Table III show the variation of resistance and reactance when $\mathrm{L}-\mathrm{G}$ fault occurs when the system is loaded (32.0+j32.0 MVA). It can be observed that higher value of impedance has to be set when STATCOM is included at the mid point of transmission line. Hence the relay may not identify the fault with its normal setting (without STATCOM), which necessitates the adaptive nature of relay setting whenever STATCOM is included in the system. 
TABLE I

VARLATION OF APPARENT RESISTANCE AND REACTANCE VALUES IN DIFFERENT LOADING CONDITIONS

\begin{tabular}{c|c|c|c|c}
\hline \multirow{2}{*}{$\begin{array}{c}\text { Load at } \\
\text { receiving end } \\
\text { (MVA) }\end{array}$} & \multicolumn{2}{c|}{$\begin{array}{c}\text { Without } \\
\text { STATCOM } \\
\text { (Ohms) }\end{array}$} & \multicolumn{2}{c}{$\begin{array}{c}\text { With STATCOM } \\
\text { (Ohms) }\end{array}$} \\
\cline { 2 - 5 } & $\mathrm{R}_{\mathrm{n}}$ & $\mathrm{X}_{\mathrm{n}}$ & $\mathrm{R}_{\mathrm{a}}$ & \multicolumn{2}{c}{$\mathrm{X}_{\mathrm{a}}$} \\
\hline $32.0+\mathrm{j} 15.5$ & 415.9 & 213.8 & 509.1 & 45.5 \\
\hline $32.0+\mathrm{j} 24.0$ & 321.0 & 246.0 & 483.3 & 22.0 \\
\hline $32.0+\mathrm{j32.0}$ & 283.3 & 249.2 & 474.2 & -8.0 \\
\hline
\end{tabular}

TABLE II

VAREATION OF APPARENT RESISTANCE AND REACTANCE VALUES OF PHASE -A WHEN L -G FAULT OCCURS AT 75\% OF THE TRANSMISSION IDNE IN ADDITION TO NORMAL LOADNG $32+132$ MVA.

\begin{tabular}{c|c|c|c|c}
\hline \multirow{2}{*}{$\begin{array}{c}\text { Fault resistance } \\
\mathbf{R}_{\mathrm{f}}\end{array}$} & \multicolumn{1}{c|}{$\begin{array}{c}\text { Without } \\
\text { STATCOM } \\
\text { (Ohms) }\end{array}$} & \multicolumn{2}{|c}{ With STATCOM } \\
\cline { 2 - 5 } & $\mathrm{R}_{\mathrm{a}}$ & $\mathrm{X}_{\mathrm{a}}$ & $\mathrm{R}_{\mathrm{a}}$ & $\mathrm{X}_{\mathrm{a}}$ \\
\hline $10 \Omega$ & 17.02 & 17.30 & 40.60 & 23.20 \\
\hline $40 \Omega$ & & & & \\
\hline $80 \Omega$ & 43.80 & 20.00 & 115.36 & 35.43 \\
\hline
\end{tabular}

TABLE III

VARIATION OF APPARIENT RESISTANCE AND REACTANCE VALUES OF PHASE- A WHEN L-G FAULT OCOURS AT $25 \%$ OF THE TRANSMISSION LINE IN ADDTTON TO NORMAL LOADING $32+\mathrm{J} 32 \mathrm{MVA}$

\begin{tabular}{c|c|c|c|c}
\hline \multirow{2}{*}{$\begin{array}{c}\text { Fault resistance } \\
\mathrm{R}_{\mathrm{f}}\end{array}$} & \multicolumn{2}{c}{$\begin{array}{c}\text { WTithout } \\
\text { (OTCOM) }\end{array}$} & \multicolumn{2}{c}{ With STATCOM } \\
\cline { 2 - 5 } & $\mathrm{R}_{\mathrm{a}}$ & $\mathrm{X}_{\mathrm{a}}$ & $\mathrm{R}_{\mathrm{a}}$ & $\mathrm{X}_{\mathrm{s}}$ \\
\hline $10 \Omega$ & 12.20 & 5.90 & 18.42 & 6.22 \\
\hline $40 \Omega$ & 39.17 & 8.55 & 63.70 & 13.82 \\
\hline $80 \Omega$ & 69.74 & 15.43 & 112.79 & 19.56 \\
\hline
\end{tabular}

The additional information needed for this setting is the reactive power supply of STATCOM. Assuming the availability of STATCOM cycle-to-cycle reactive power information by carrier communication, it is possible to calculate the actual values of resistance and reactance, so that distance relay setting can be modified accordingly. Mid point compensation has an advantage that it effectively reduces the line reactance to half the value. So the reactive power needed for the STATCOM is less when compared to the supply of the reactive power from sending end (in the absence of STATCOM) in order to maintain the same voltage profile. Approximate values of resistance and reactance can be evaluated using (3) and (4), by replacing reactive power term with the sum of reactive power at sending end and reactive power from STATCOM.

\section{IMPLEMENTATION}

The relay design comprises of hardware and software. The hardware set-up for the implementation of adaptive distance relay for transmission line protection is shown in Fig. 8. The data files containing the samples of instantaneous voltage and currents obtained from simulation studies of PSCAD/EMTDC model are reproduced using the waveform simulator. New settings of distance relay have been calculated using active power, reactive power flows at the sending end and reactive power of the STATCOM. Quadrilateral characteristic has been realized for distance relaying scheme for both the cases of with and without STATCOM. Since resistance and reactance can be independently controlled, the proposed scheme can be used for applications in adaptive relaying.

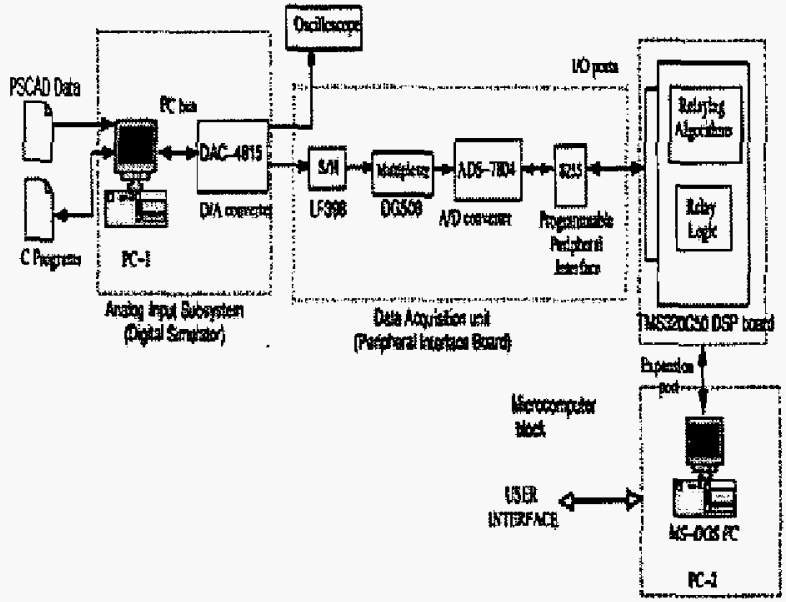

Fig. 8. Hardware setup for implementation Adaptive distance relay

The waveform simulator generates the relaying signals on a real-time basis using a 12-bit Digital to Analog converter card interfaced to $\mathrm{PC}$. The relaying hardware has been built using Texas Instruments TMS320C50 DSP processor [10]. A 12-bit Analog-to-Digital Converter (ADC) with a conversion time of 7.6 $\mu$ s has been interfaced to the DSP hardware to acquire incoming samples of voltages and currents. To achieve simultaneous sampling of all the voltage and current signals, eight S/Hs (LF398- Burr Brown) are used in the ADC card. The $\mathrm{ADC}$ card is interfaced to the Texas Instruments TMS320C50 DSP processor by the Intel Programmable Peripheral interface IC 8255. The TMS320C50 DSP has the following important features such as $\mathbf{4 0} \mathrm{ns}$ single-cycle fixedpoint instruction execution time, single cycle multiply/accumulate (MAC) instructions, $9 \mathrm{~K} \times 16$-bit single cycle on chip program/data RAM and 16 bit programmable timer. 
The relaying software including the signal conditioning, signal acquisition, processing of data and the relaying logics for relay characteristic are written in the assembly language of the TMS320C50 DSP processor. The Fourier Full cycle algorithm with 12-sample window has been used to evaluate the magnitude of incoming signals and to calculate the resistance and reactance. The relay characteristic has been tested using all the simulated cases of PSCAD/EMTDC. With the presence of STATCOM, the reach settings of the relay have been modified in the digital relaying program. The time required for the processing of relaying algorithm including the relay logic is about $120 \mu \mathrm{s}$.

\section{CONCLUSIONS}

The presence of FACTS devices such as STATCOM changes the apparent resistance and reactance values of distance relay as outlined in the above simulation studies. Both normal loading and fault cases have been studied. In the normal loading conditions with STATCOM, resistance values are more and reactance values are less when compared to the resistance and reactance values without STATCOM. The fault case studies show that both resistance and teactance values are increased with STATCOM when compared to the case without STATCOM. For the protection of transmission line involving STATCOM, it is identified that there is a need for the distance relay to adapt to the new settings in its characteristic for fault detection within the zone of the protection. The most frequent fault namely L-G fault has been considered for simulation studies. The data from PSCAD/EMTDC simulation has been reproduced for DSP implementation. New settings of the distance relay have been calculated using active, reactive powers of sending end and reactive power of STATCOM. The DSP based implementation of digital distance relay scheme is suitable for adaptive relaying applications since both resistance and reactance settings are independently controlled.

\section{RFFERENCES.}

[1] A.G. Phadke, S.H. Horowitz, "Adaptive Relaying", Computer Applications in Power, IEEE, Vol. 3, pp. 47-51, July 1990.

[2] T.S. Sidhu, "Computer-based protection: recent advances and future directions", TENCON 198, Proc, of IEEE Region 10 Intl Conf. on Glabal Connectivity in Energy, Comp, Comm., and Control, Vol. 2, pp. 424-427, Dec. 1998

[3] P.K. Dash, A. K. Pradhan, Ganapati Panda, and A. C. Liew, "Adaptive Relay Setting for Flexible AC Transmission Systems (FACTS)", IEEE Trans. Power Delivery, VoL. 15, pp. 38-43, Jan. 2000.

[4] Khalil El-Arroudi, G. Joos, D.T. McGillis, "Operation of Impedance Protection Relays With the STATCOM", IEEE Trans. Power Delivery, Vol. 17,pp.381-387, April 2002.

[5] User's guide PSCAD 4.0.1, Manitoba-HVDC research center, Canada 2003

[6] C. Schauder, L. Gyugyi, M. R. Lund, D. M. Hamai, T. R. Rietman, D. R. Torgerson, A. Edris, "Operation of \pm 100 MVar TVA STATCON", IEEE Trans. Power Delivery, Vol. 12, pp. 1805-1811, Oct. 1997.

[7] L. Gyugyi, "Dynamic Compensation of AC Transmission Lines by Solid-State Synchronous Voltage Sources", IEEE Trans. Power Delivery, vol. 9, pp. 904-911, Apr 1994

[8] Olimpo Anaya-Lara, E. Acha, "Modeling and Analysis of Custom Power Systems by PSCAD/EMTDC", IEEE Trans. Power Del., Vol. 17, pp. 266-272, Jan. 2002
[9] T. S. Sidhu, D. S. Ghotra, and Mohindar S. Sachdev, "An Adaptive Distance Relay and its Performance Comparison With a Fixed Data Window Distance Relay", IEEE Trons. Power Defivery, vol. 17, pp. 691-697, July 2002

[10] “TMS320C5X User's Guide”, Texas Instruments, USA, Jan, 1993.

\section{BIOGRAPHIES}

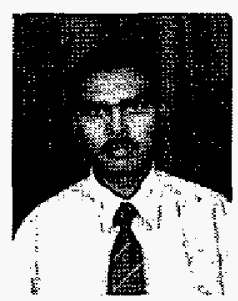

J. V. V. N. Bapiraju reccived his B.Tech degree in Electrical Engineering from J. N. T. U. College of Engineering, Hyderabad in 2002. He is currently doing his $M$. E in the Department of Electrical Engineering, Indian Institute of Science, Bangalore. His current research interests include digital protective relaying, DSP techniques in power system protection, and FACTS

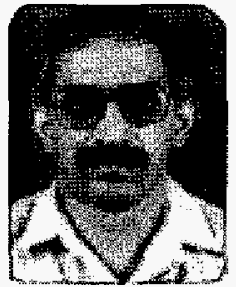

U. J. Shenoy received the B.E. degree in Electronics and Communications from Mysore University in 1979, M.Sc. (Research) in 1986 and Ph.D. degree in 1995 both in Electrical Engineering from the Indian Institute of Science, Bangalore. Since 1984 he has been with Indian Institute of Seience as a Scientific staff and presently be is Seaior Scientific Officer. He has authored/co-authored more than 30 papers published in nationalinternational conferences and professional jounnals. His research interests include DSP and AI applications in power system protection, AC traction systems.

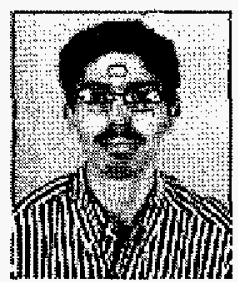

K. G. Sheshadri received the B.E. degree in Electrical Engineering from U.V.C.E College, Bangalore University in 2000. He worked for a private company and joined as a Project Assistant in the Electrical Engineering Department, Indian Institute of Science at Bangalore in 2002. He is currently working as Project Assistant in this department where he has co-authored four papers. His current research interests include digital protective relaying, DSP techniques in power system protection, AI applications to power system protection and analysis of $\mathrm{AC}$ traction systems.

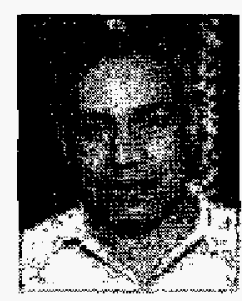

H.P. Khincha received the B.E. degree in Electrical Engineering from Bangalore University in 1966. He received M.E. degree in 1968 and Ph.D. degree in 1973 both in Electrical Engineering from the Indian Institute of Science, Bangalore. Since 1973 he has been with Indian Institute of Science, Bangalore as faculty where currently he is Professor. His research interests include computer aided power system aualysis, power system protection, distribution automation and $\mathrm{AI}$ applications in power systems.

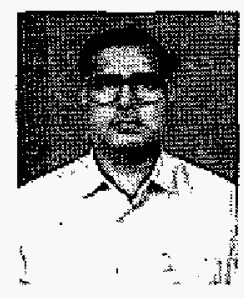

D.Thukaram received the B.E. degree in Electrical Engineering from Osmania University, Hyderabad in 1974, M. Tech degree in Integrated Power Systems from Nagpur Unjversity in 1976 and Ph.D. degree from lndian Institute of Science, Bangalore in 1986. Since 1976 be has been with Indian Institute of Science as a research fellow and faculty in various positions and currently be is Professor. His research interests include computer aided power system Analysis, reactive power optimization, voltage stability, distribution automation and AI applications in power systems. 